\title{
A Primary Permanent-Magnet Linear Motor for Urban Rail Transit
}

\author{
Ruiwu Cao ${ }^{* * * *}$, Ming Cheng", Chris Mi**, Wei Hua* and Wenxiang Zhao ${ }^{* * *}$
}

\begin{abstract}
In this paper, a new permanent-magnet (PM) linear motor is proposed, in which both the magnets and armature windings are placed in the short mover, while the long stator consists of iron core only. Hence, this new PM linear motor can be called a primary permanent-magnet linear motor. It exhibits the advantages of robustness, low cost, high efficiency, high power factor, and high thrust force density. It is especially suitable for long stator applications such as urban rail transit. In this paper, the topology and operation principle of this motor are discussed in detail. The steady-state characteristics including field distributions, flux-linkage, back-EMF, phase inductance and thrust force are investigated. In addition, the technique of skewing stator teeth is adopted to improve the electromagnetic performance. Results from finite element method (FEM) verified the theoretical analysis results.
\end{abstract}

Keywords: Doubly salient motor, Permanent-magnet machine, Linear motor, Urban rail transit

\section{Introduction}

Currently, the main types of traction motors used for urban rail transit (URT) can be classified as rotating motors and linear motors. It has been found that direct linear drive motors have the benefits of faster dynamic performance, improved reliability, lower noise, and higher efficiency due to the fact that energy conversion from rotary to linear motion is not required [1]-[3]. The conventional permanentmagnet (PM) linear motor exhibits higher efficiency and power factor than the induction linear motor [4]. However, in the long stator applications such as URT, this solution inevitably results in a significant cost increase due to the fact that numerous magnets or armature windings are set in the stator. In recent years, a new class of PM brushless motors with PMs in the stator, namely the doubly-salient PM (DSPM) motor [5]-[10], has received a lot of attention due to its high power density, its robust mechanical integrity, and the fact that it does not suffer from the problem of thermal dissipation.

Based on the rotary DSPM motor, a new primary PM linear (PPML) motor is proposed and investigated in this paper. First, the topology and operation principle of the proposed PPML motor will be presented in Section 2. Then, the technique of using additional teeth for reducing the cogging force, and for balancing the flux leakage that

\footnotetext{
* School of Electrical Engineering, Southeast University, Nanjing, China. (mcheng@seu.edu.cn)

** Dept. of Electrical and Computer Engineering, University of Michigan, Dearborn, USA.

*** School of Electrical and Information Engineering, Jiangsu University, Zhenjiang, China.

Received 17 June 2011 ; Accepted 15 November 2011
}

results from the end effect, will be discussed, also in Section 2. Thirdly, the electromagnetic performance of the proposed PPML motor will be investigated in Section 3. Finally, the influence of the skewed stator on the electromagnetic characteristics of the PPML motor will be discussed in Section 4. Finite element method (FEM) is employed to verify the effectiveness of the proposed motor.

\section{Topology and Principle}

\subsection{Topology}

Borrowing from the rotary topology of a 12-stator-slot/8rotor-pole three-phase DSPM motor [11], a new PPML motor is proposed, as shown in Fig. 1(a), in which both the PMs and the armature windings are set on the short primary mover while the long secondary stator is made only of iron. For the URT application, the primary should be set at the steering device of the train, while the iron stator should be fixed between the two rails along the whole line. Fig. 1(b) shows the cross-section and configuration of the proposed PPML motor. In order to balance the magnetic circuit of the end part of the armature winding, additional teeth are set at each end of the primary mover. Also, five pieces of magnets are inserted in the mover iron yoke. These five pieces are magnetized with magnetic fields that alternate in direction (one N-S, the next S-N, and so on). In addition, similar to the DSPM motor, the PPML motor employs concentrated armature windings on the mover teeth, except for the case of the additional teeth. The basic design dimensions of the PPML motor are listed in Table 1. 


\subsection{Operation Principle}

Assuming that the fringing and end effect are negligible, and that the permeability of the core is infinite, the result is a linear variation of PM flux linkage, and therefore a rectangular graph for the back-EMF, in each mover winding at no-load, as shown in Fig. 2. Hence, theoretically, a constant thrust force can be achieved by applying a rectangular current in phase with the back-EMF waveform to the winding, i.e., a positive current when the PM flux is increasing and a negative current when the PM flux is decreasing.

Fig. 3 shows the cogging force waveforms of three topologies, Fig. 4 shows the partial back-EMF waveforms of three topologies.

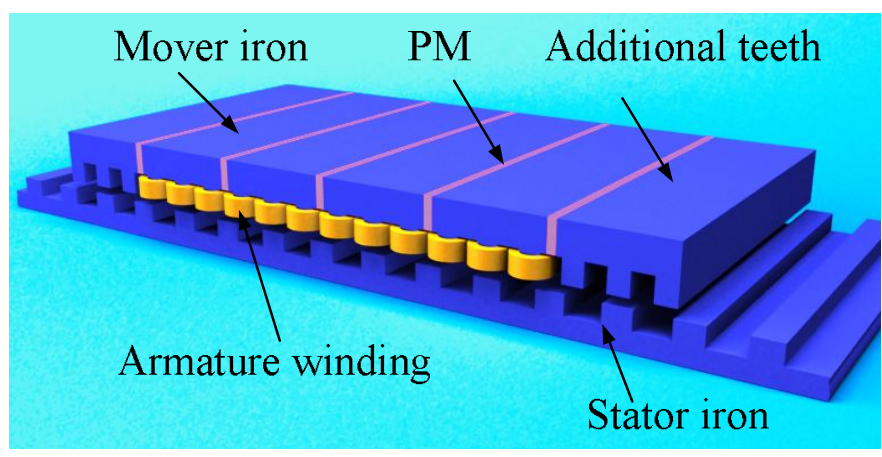

(a)

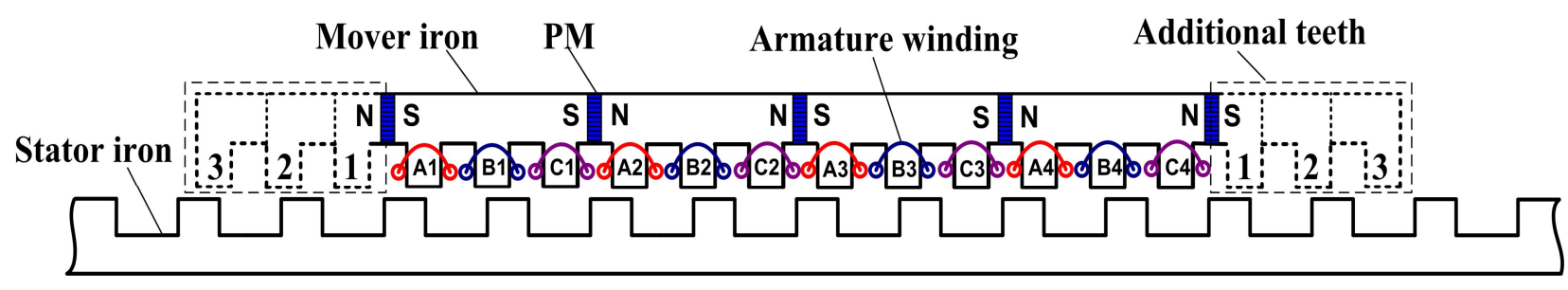

(b)

Fig. 1. Topology of PPML motor. (a) Configuration. (b) Cross-section.

Table 1. Design Specifications of PPML Motor

\begin{tabular}{l|l}
\hline \hline Item & Value \\
\hline Rated speed $(\mathrm{m} / \mathrm{s})$ & 3 \\
Mover and stator width $(\mathrm{mm})$ & 75 \\
Mover yoke height $(\mathrm{mm})$ & 26 \\
Mover slot height $(\mathrm{mm})$ & 19 \\
Mover pole pitch $\tau_{\mathrm{m}}(\mathrm{mm})$ & 33 \\
Stator pole pitch $\tau_{\mathrm{s}}(\mathrm{mm})$ & 49.5 \\
Mover tooth width $(\mathrm{mm})$ & 16.5 \\
Stator tooth width $(\mathrm{mm})$ & 22 \\
Stator tooth height $(\mathrm{mm})$ & 15 \\
Stator yoke height $(\mathrm{mm})$ & 17 \\
Total magnet volume $\left(\mathrm{mm}{ }^{3}\right)$ & $7 * 26^{*} 75^{* 5}$ \\
Magnet remanence $(\mathrm{T})$ & 1.2 \\
Air gap length $(\mathrm{mm})$ & 0.6 \\
Number of turns per coil & 74 \\
Rated peak current $(\mathrm{A})$ & 4.69 \\
\hline \hline
\end{tabular}
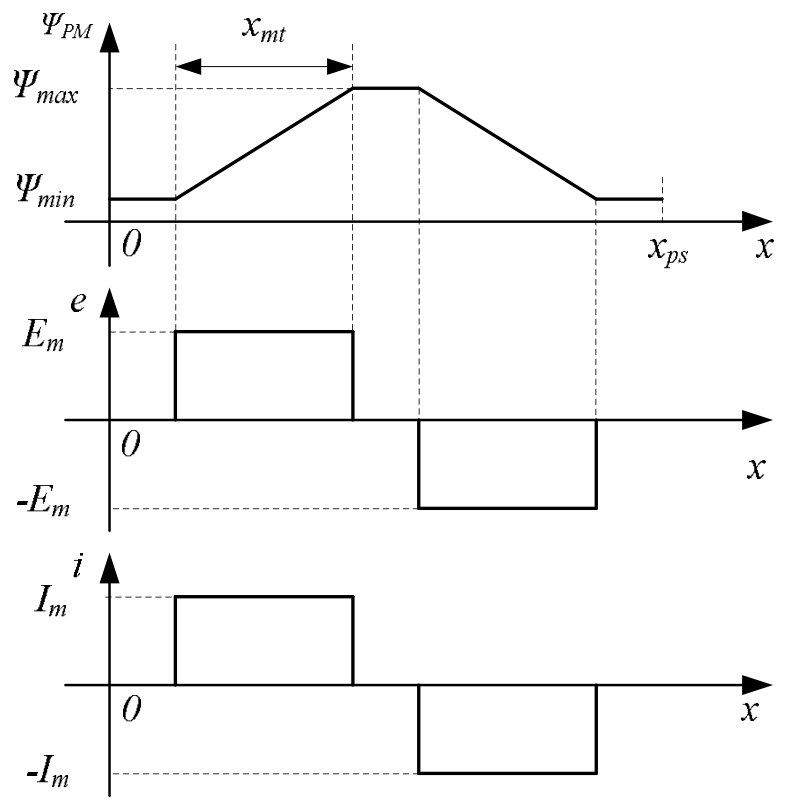

Fig. 2. Operation principle 


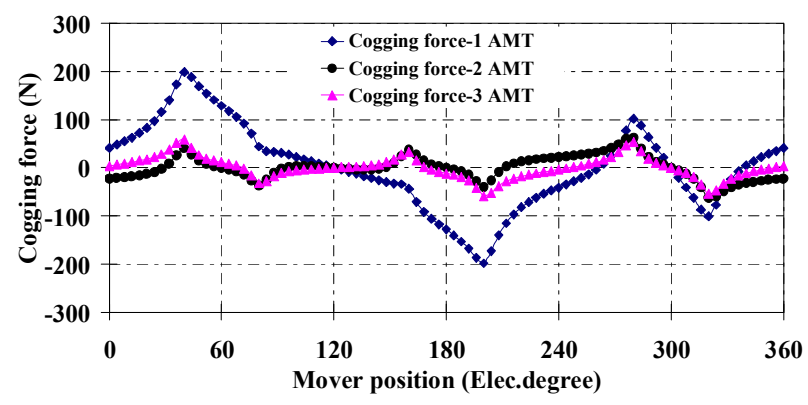

Fig. 3. Cogging force waveforms of three topologies

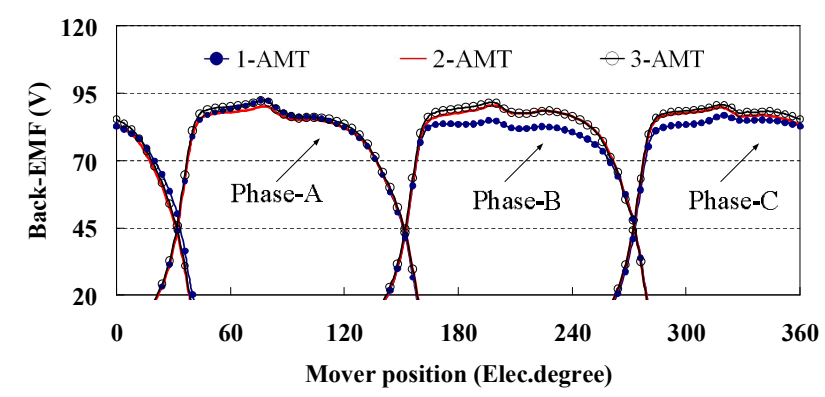

Fig. 4. Partial back-EMF waveforms of three topologies

\section{Static Performance Analysis}

\subsection{Field Distributions}

Fig. 5(a) shows the open-circuit field distribution and Fig. 5(b) shows the air-gap flux density from position "a" to position "b", where the flux linkage of the phase-A coils is at the minimum value. It can be seen that the air-gap flux density is non-sinusoidal and the peak air-gap flux density is nearly $1.5 \mathrm{~T}$.

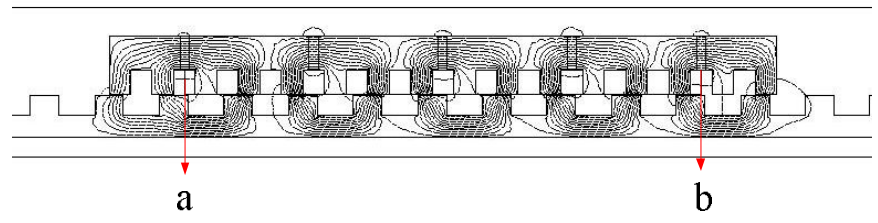

(a)

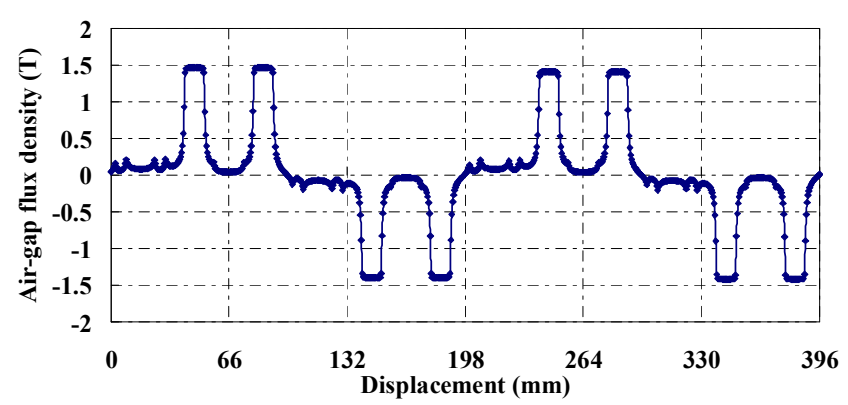

(b)

Fig. 5. Flux performance. (a) Flux distribution. (b) Airgap flux density.

\subsection{Flux Linkage and Back-EMF}

The three phase flux-linkage waveforms of the proposed PPML motor are shown in Fig. 6. Obviously, the three phase flux-linkage waveforms are symmetrical and balanced, as well as nearly free from end effect. The induced back-EMF is given as where $x$ is the mover part

$$
e=\frac{d \psi_{m}}{d t}=\frac{d \psi_{m}}{d x} \cdot \frac{d x}{d t}=\frac{d \psi_{m}}{d x} \cdot v
$$

displacement, $v$ is the mover speed, and $\psi_{m}$ is the fluxlinkage excited by PM only. Fig. 7 depicts the three phase back-EMF waveforms of the proposed PPML motor by using FEM. It can be observed that the back-EMF waveforms are perfectly symmetrical. This is because the additional teeth balance the end part magnet circuit.

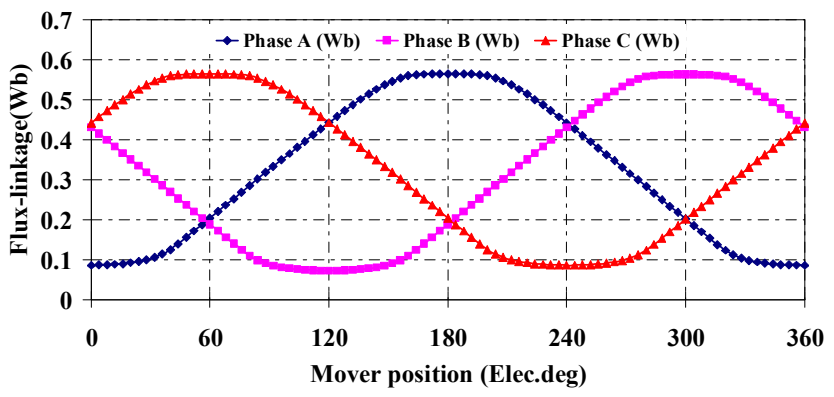

Fig. 6. Flux-linkage waveforms

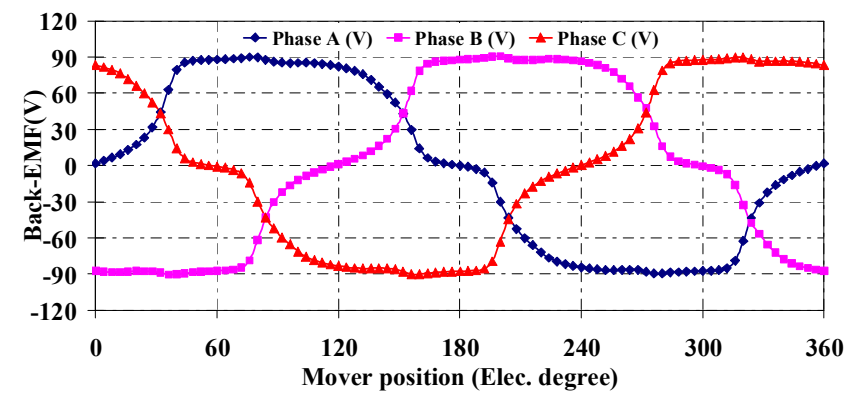

Fig. 7. Back-EMF waveforms

\subsection{Inductances and Thrust Forces}

In order to calculate the inductance accurately, the method considering magnetic saturation is adopted [6].

$$
L=\left(\psi-\psi_{p m}\right) / i
$$

where $\psi$ is the combined flux-linkage of phase A produced by both PM and the phase current, $\psi_{p m}$ is the PM fluxlinkage provided by PM only, $L$ is the inductance of one phase, and $i$ is the phase current. 
Fig. 8 shows the inductance characteristics of the proposed DSPM motor, where "Laa+4.69A" and "Laa4.69A" denote the strengthening and weakening actions of the armature flux (with the phase current of $4.69 \mathrm{~A}$ ) to the PM flux, respectively. It is noted that the inductance under "Laa+4.69A" is lower than that under "Laa-4.69A" because of higher saturation under "Laa+4.69A."

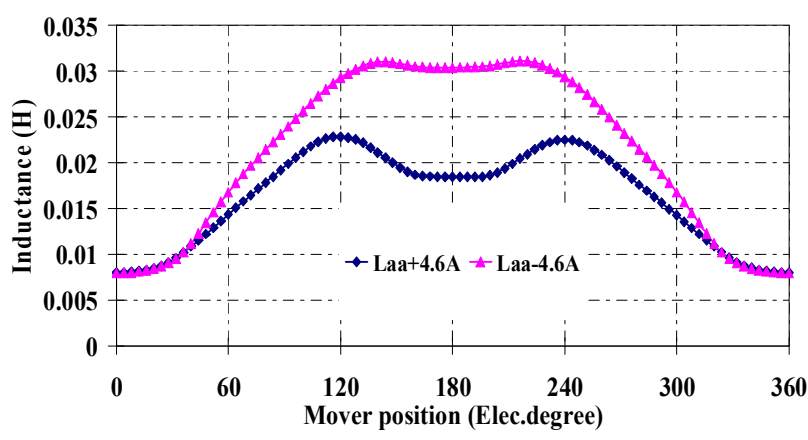

Fig. 8. Inductance waveforms

Fig. 9 shows the rated static thrust force, in which the proposed PPML motor with 2 AMT

operates in the conventional $120^{\circ}$ brushless DC (BLDC) mode, and it also shows the cogging force waveforms. Apparently, similar to that of a rotary DSPM motor, the thrust force ripple is relatively high due to the doublysalient structure. The detailed results are summarized in Table 2.

Fig. 10 shows the thrust force of the proposed motor for different currents in BLDC operation mode.

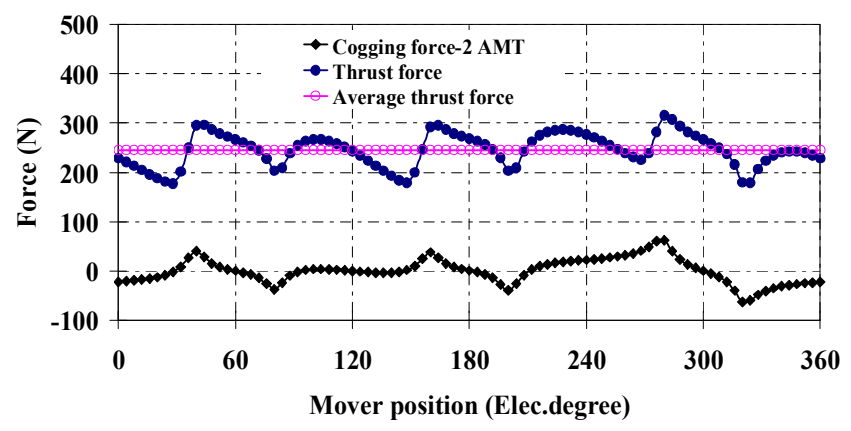

Fig. 9. Rated static thrust force waveforms of PPML motor

Table 2. Characteristics of thrust force and cogging force

\begin{tabular}{ccc}
\hline \hline Item & Cogging force & Thrust force \\
\hline $\mathrm{F}_{\max }(\mathrm{N})$ & 62.3 & 315.2 \\
$\mathrm{~F}_{\min }(\mathrm{N})$ & -62.5 & 177.1 \\
$\mathrm{~F}_{\text {ave }}(\mathrm{N})$ & -0.25 & 245.3 \\
$\mathrm{~F}_{\text {ripple }}(\mathrm{N})$ & 124.7 & 138.1 \\
\hline \hline
\end{tabular}

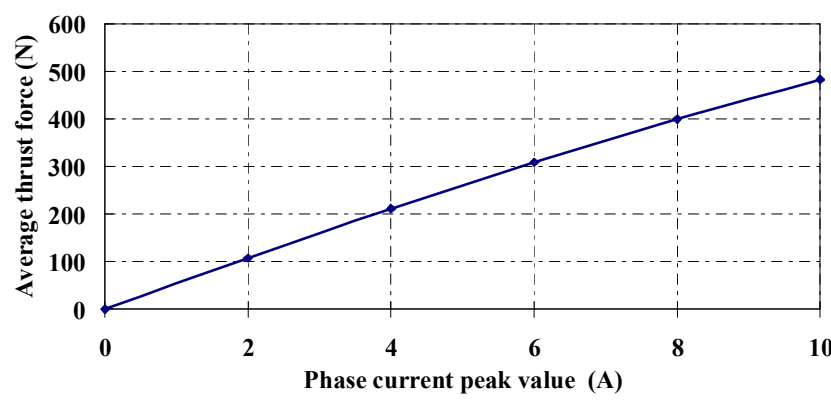

Fig. 10. Static thrust force versus peak phase current

\section{Effect of Stator Teeth Skewing}

It can be seen from Table 2 that the cogging force and thrust force ripple of the proposed PPML motor are relatively high. In order to minimize the DSPM motor cogging torque, a skewed rotor teeth

method was proposed in [12]-[13]. Since the stator of the proposed PPML motor is also very simple, the skewed stator teeth method is adopted for the PPML motor, as shown in Fig. 11. The static characteristics, including the PM flux-linkage, back-EMF, inductance, and cogging force, can be obtained from the un-skewed 2-D FEM results as follows:

$$
f^{\prime}\left(x_{s}\right)=\frac{1}{2 N+1}\left\{f\left(x_{s}\right)+\sum_{k=1}^{N}\left[f\left(x_{s}-\frac{k \delta}{2 N}\right)+f\left(x_{s}+\frac{k \delta}{2 N}\right)\right]\right\}
$$

where $f\left(x_{s}\right)$ and $f^{\prime}\left(x_{s}\right)$ denote the static characteristics of the proposed PPML motor with skewed stator teeth, and without skewed stator teeth, respectively. $2 N$ is the number of segments of stator teeth along the teeth width axis, $\delta$ is the skewing displacement, and $k$ is the temporary variable iteration.

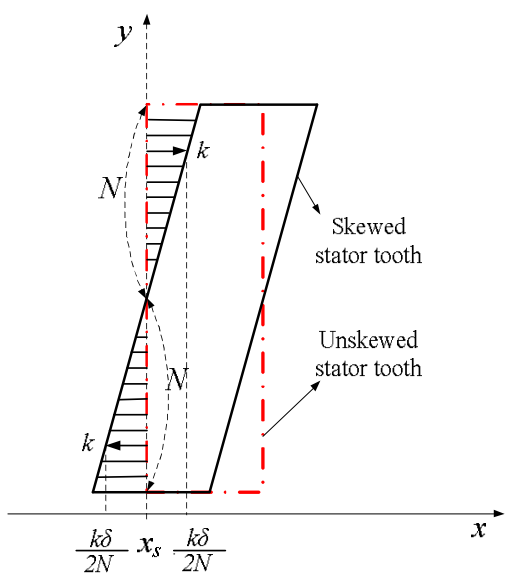

Fig. 11. The top view of the stator teeth skewed model 
Fig. 11 shows the top view of the skewed stator teeth model. The $x$ - and $y$-axes denote the direction of mover motion and the width dimension of the mover teeth, respectively. At position $x_{\mathrm{s}}$, the static characteristics of the PPML motor with skewed teeth can be modeled as the average of the static characteristics of the motor with un-skewed stator teeth, at a series of mover positions from $x_{\mathrm{s}}-\delta / 2$ to $x_{\mathrm{s}}+\delta / 2$. The influences of skewed stator teeth on the back-EMF and cogging force waveforms are shown in Fig. 12.

In the process of computation, one period is divided into 90 steps, that is, the stator pole pitch is divided into 90 segments. Hence, "Skewed_10" (in Fig. 12) denotes that the skewing displacement is $10 \tau_{\mathrm{s}} / 90$. Obviously, the skewed stator teeth method can improve the back-EMF waveform so that it is more sinusoidal, and it can significantly reduce the cogging force.

It should be noted that, by skewing the stator teeth, the peak back-EMF is reduced to some extent, which is unfavorable for the thrust force production. So, considering both the reduction and the total harmonic distortion in the back-EMF, "Skewed 34" is adopted in this PPML motor.

Fig. 13 compares the back-EMF and cogging force waveforms with and without "Skewed 34" stator teeth. Apparently, after skewing, the back-EMF waveform is close to the ideal sinusoidal shape, indicating that the brushless AC (BLAC) operation is suitable for this motor. In addition, the cogging force is reduced significantly, which is beneficial since it leads to BLAC operation with minimum force ripple.

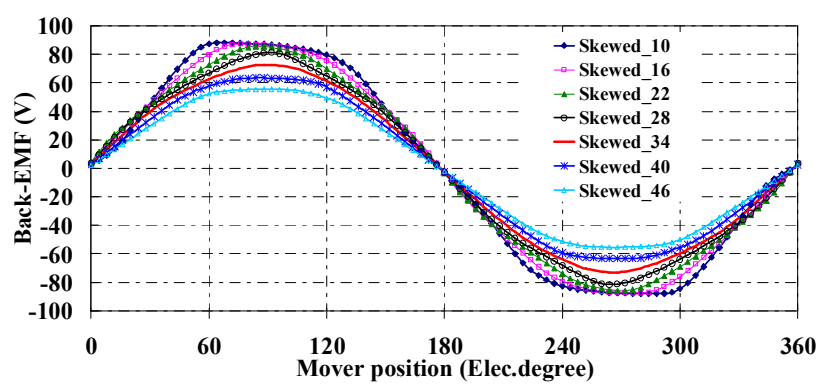

(a)

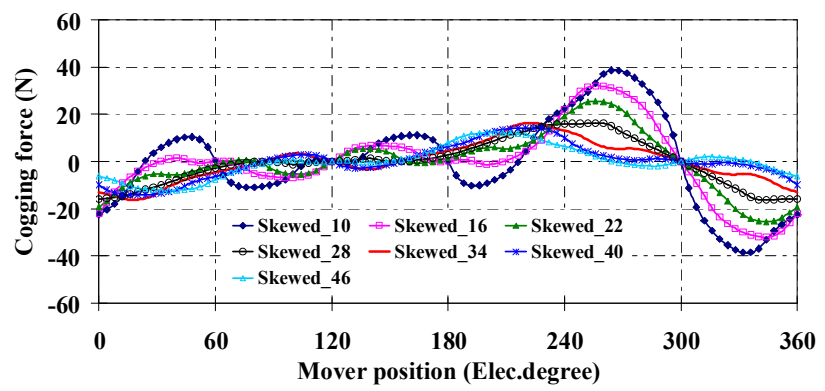

(b)

Fig. 12. Back-EMF and cogging force waveforms of PPML motor with different skewing teeth. (a) Back-EMF. (b) Cogging force.

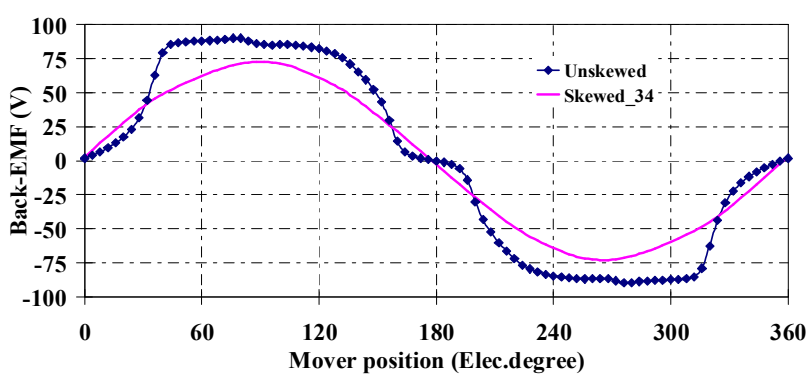

(a)

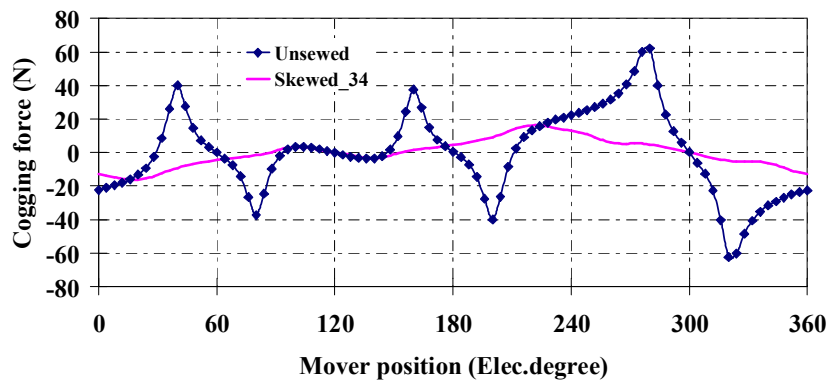

(b)

Fig. 13. Back-EMF and cogging force waveforms of PPML motor with and without skewing stator teeth. (a) Back-EMF. (b) Cogging force.

Fig. 14 compares the self-inductance under PMstrengthened "Laa+4.6A" and PM-weakened "Laa-4.6A" conditions with and without skewing stator teeth. It can be seen that in both cases the self-inductance waveforms for the case of skewed stator teeth are more sinusoidal than those for the case of un-skewed stator teeth.

Moreover, when the sinusoidal phase currents are applied to the windings in phase with the back-EMF, the average static electromagnetic thrust force can be expressed as

$$
F_{e m}=F_{p m}+F_{r}=\frac{e_{m a}+e_{m b}+e_{m c}}{v}+F_{r} \approx \frac{3}{2} \frac{E_{m} I_{m}}{v}
$$

where $e_{m a}, e_{m b}, e_{m c}$, are the three phase back-EMFs, $v$ is the motor speed, $E_{\mathrm{m}}$ and $I_{\mathrm{m}}$ are the peak back-EMF and peak phase current, respectively, $F_{p m}$ is the PM thrust force, and $F_{r}$ is the reluctance force, which is negligible compared to the PM thrust force.

Based on the above analysis, the thrust force (including the cogging force) for the case of the motor with "Skewed 34" stator teeth, and for the case of the motor without skewed teeth, under the same root-mean-squared (RMS) phase current, is shown in Fig. 15. The detailed information is listed in Table 3. Obviously, the average thrust force of the skewed-teeth motor is about $80 \%$ of that of the un-skewed structure, while the force ripple is about $23.6 \%$ of that of the un-skewed motor. 


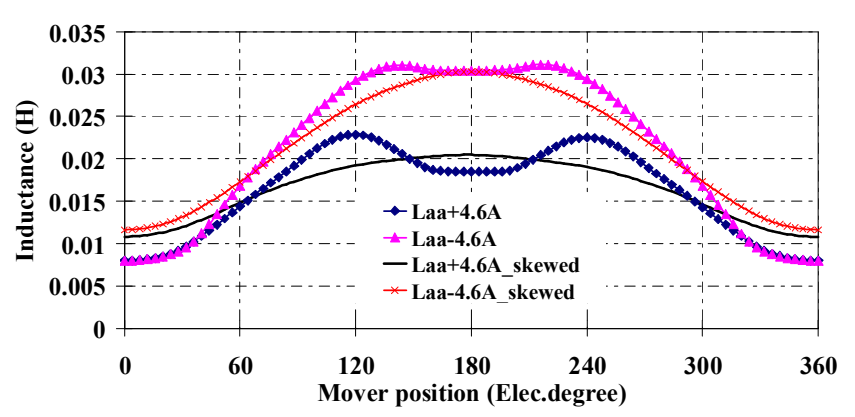

Fig. 14. Phase inductances for different stator teeth

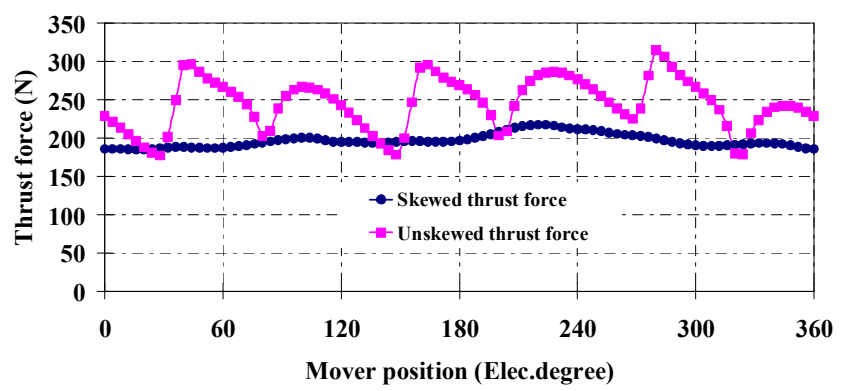

Fig. 15. Thrust force of PPML motors with different stator teeth

Table 3. Thrust force capability comparison

\begin{tabular}{ccc}
\hline \hline Item & Skewed stator teeth & $\begin{array}{c}\text { Un-skewed stator } \\
\text { teeth }\end{array}$ \\
\hline$F_{\max }(\mathrm{N})$ & 217.6 & 315.2 \\
$F_{\min }(\mathrm{N})$ & 184.9 & 177.1 \\
$F_{\text {ave }}(\mathrm{N})$ & 196.6 & 245.3 \\
$F_{\text {ripple }}(\mathrm{N})$ & 32.6 & 138.1 \\
\hline \hline
\end{tabular}

\section{Conclusion}

In this paper, a new primary PM linear motor, in which the magnets and windings are all set on the short primary mover, while the long stator is made of iron only, was proposed and analyzed. This motor incorporates the merits of DSPM motors and the merits of linear motors, which are perfectly suited for long stator applications, such as urban rail transit, resulting in a considerable reduction of system cost. Additional teeth were added at each end part of the primary mover of the motor, and this structure was studied. This method (of adding additional teeth) was shown to make the proposed motor free from end effect and was shown to reduce the cogging force. Analytical results of the electromagnetic characteristics, based on this structure, were obtained and then confirmed by using FEM. Finally, the skewed stator teeth technique was adopted in this motor to reduce the cogging force and eliminate the higher harmonics in the back-EMF. These improvements make the motor suitable for BLAC operation and lead to minimum thrust force ripple. The proposed PPML motor topology and design method have a bright future in urban rail transit applications.

\section{Acknowledgements}

This work was supported in part by National Natural Science Foundation of China (Project No: 50907031), the Specialized Research Fund for the Doctoral Program of Higher Education of China (Project No: 20090092110034), the 2010 Foundation Project of Technology Innovation for Graduates in Jiangsu Province (X10B 066Z), and the Fund Program of Southeast University for Excellent Youth Teachers.

\section{References}

[1] J. F. Gieras and Z. J. Piech, Linear Synchronous Motors: Transportation and Automation Systems. Boca Raton, FL: CRC, 2000.

[2] A. Boldea and S. Nasar, Linear Electromagnetic Devices. New York: Taylor \& Francis, 2001.

[3] R. Cao, M. Cheng, W. Hua; W. Zhao, and X. Sun, "Comparative study of linear double salient permanent magnet motors," Electromagnetic Field Computation (CEFC), 2010 14th Biennial IEEE Conference on , vol., no., pp.1-1, 9-12 May 2010.

[4] G. Stumberger, D. Zarko, M. T. Aydemir, and T. A. Lipo. "Design and comparison of linear synchronous motor and linear induction motor for electromagnetic aircraft launch system," International Electric Machines and Drives Conference, pp. 494-500, 2003.

[5] Y. Liao, F. Liang and T. A. Lipo, "A novel permanent magnet machine with doubly salient structure," IEEE Trans. Ind. Appl., vol. 31, no. 5, pp.1069-1078, 1995.

[6] M. Cheng, K. T. Chau, and C. C. Chan, "Design and analysis of a new doubly salient permanent magnet motor," IEEE Trans. Magn., vol. 37, No. 4, pp. 3012-3020, July 2001.

[7] M. Cheng, K. T. Chau, C. C. Chan, "Static characteristics of a new doubly salient permanent magnet motor," IEEE Trans. Energy Conversion, vol. 16, no. 1, pp. 20-25, 2001.

[8] M. Cheng, K. T. Chau, C. C. Chan and Q. Sun, "Control and operation of a new 8/6-pole doubly salient permanent magnet motor drive," IEEE Trans. Ind. Appl., vol. 39, no. 5, pp. 1363-1371, 2003.

[9] K. T. Chau, C. C. Chan, and C. Liu. "Overview of permanent-magnet brushless drives for electric and hybrid electric vehicles," IEEE Trans. Ind. Electron., vol. 55, no. 6, pp. 2246-2257, 2008.

[10] W. Zhao, M. Cheng, X. Zhu, W. Hua, X. Kong “Analysis of fault-tolerant performance of a doubly salient permanentmagnet motor drive using transient cosimulation method," IEEE Trans. Ind. Electron., vol. 55, no. 4, pp. 1793-1748, Jun. 2008. 
[11] W. Zhao, K. T. Chau, M. Cheng, J. Ji, and X. Zhu, "Remedial brushless AC operation of fault-tolerant doubly-salient permanent-magnet motor drives," IEEE Trans. Ind. Electron., vol. 57, no. 6, pp. 2134-2141, Jun. 2010.

[12] W. Hua, M. Cheng "A new model of vector-controlled doubly-salient permanent magnet motor with skewed rotor" Proceedings of International Conference on Electrical Machines and Systems, Wuhan, China, 2008: 3026-3031.

[13] M. Cheng, W. Hua, X. Zhu, et al, "A simple method to improve the sinusoidal static characteristics of doubly-salient PM machine for brushless AC operation", Proc. 10th International Conference on Electrical Machines and Systems, Soul, Korea, 8-11 October, 2007, CD-ROM, 665669.

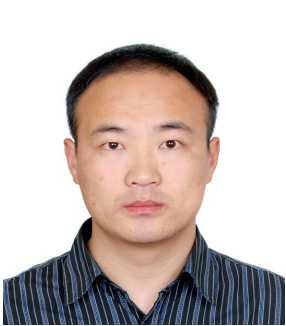

Ruiwu Cao received the B.Sc. degree from Yancheng Institute of Technology, Yancheng, China, in 2004, and the M.Sc. degree from Southeast University, Nanjing, China, in 2007, both in electrical engineering. He is currently working toward the Ph.D. degree in electrical engineering at Southeast University, Nanjing, China.

Currently, he is a joint Ph.D. student with the University of Michigan, Dearborn. His areas of interest include the design and control of novel permanent magnet machines.

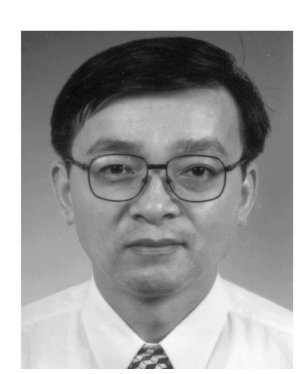

Ming Cheng received the B.Sc. and M.Sc. degrees from the Department of Electrical Engineering, Southeast University, China, in 1982 and 1987, respectively, and $\mathrm{Ph} . \mathrm{D}$. degree from the Department of Electrical and Electronic Engineering, The University of Hong Kong, Hong

Kong, in 2001.

Since 1987, he has been with Southeast University, where he is currently a Professor in the School of Electrical Engineering and the Director of the Research Center for Wind Power Generation. His teaching and research interest include electrical machines, motor drives for electric vehicles and renewable energy generation. He has authored or coauthored over 200 technical papers and 4 books, and holds 45 patents in these areas.

Prof. Cheng is a Fellow of IET and Senior Member of IEEE. He has served as chair and organizing committee member for many international conferences. 